\title{
Ocular Complications of Strabismus Surgery
}

\author{
Nazife Sefi Yurdakul, Feray Koç \\ Department of Ophthalmology, Izmir Atatürk Education and Research Hospital, Izmir, Turkey \\ Email: nsefi@yahoo.com
}

Received 13 July 2014; revised 10 August 2014; accepted 5 September 2014

Copyright (C) 2014 by authors and Scientific Research Publishing Inc.

This work is licensed under the Creative Commons Attribution International License (CC BY). http://creativecommons.org/licenses/by/4.0/

(c) (i) Open Access

\begin{abstract}
Background: To evaluate ocular complications of strabismus surgery at the Department of Strabismus and Neuroophthalmology in our clinic. Methods: The medical records of patients who underwent strabismus surgery between March 1999 and February 2013 were retrospectively reviewed. Patients with minor ocular complications such as wound irregularities, conjunctivitis, subconjunctival hemorrhage, and less than six-month follow-up periods were excluded from the study. Employed strabismus surgeries included recessions, resections, muscle advancements, inferior oblique myectomies, and muscle transpositions. Results: Our case series are comprised of 1468 patients who underwent strabismus surgery. The ages of the patients ranged from 6 to 80 years. Recognized primary ocular complications were noted in eight patients $(0.5 \%)$. Scleral perforation with retinal break was observed in one myopic patient during retrobulbar anesthesia. Medial rectus rupture occurred during medial rectus recession in one patient with chronic complete sixth nerve palsy. Conjunctival cyst occured postoperatively in one patient with partially refractive accommodative esotropia who had bilateral medial rectus recession. Corneal dellen developed postoperatively in five patients with exotropia. Conclusion: Ocular complications of strabismus surgery are usually treatable. Damage to ocular structures can be prevented by meticulous surgical approach. Close postoperative follow-up is required in all cases.
\end{abstract}

\section{Keywords}

Complications, Strabismus, Surgery

\section{Introduction}

Complications are unavoidable results of any procedure, including strabismus surgery. Fortunately, ocular complications in strabismus surgery are uncommon, and usually treatable. Scleral perforations and penetrations, slipped or lost muscles, orbital and ocular inflammations, infections, anterior segment ischemia, conjunctival cysts, pyogenic or suture granulomas, wound irregularities, corneal dellen and fat adherence syndrome are some 
of the complications of strabismus surgery [1]-[3]. Among these, scleral perforation and endophthalmitis are rare but devastating. However, the incidence of these complications has greatly diminished in recent years, with the use of spatulated needle, and loupe or microscope magnification during surgery [4] [5]. In this study we aimed to evaluate the identified major ocular complications of strabismus surgery at the Department of Strabismus and Neuroophthalmology in our clinic.

\section{Materials and Methods}

The medical records of patients who underwent strabismus surgery between March 1999 and February 2013 were reviewed for the occurrence of ocular complications retrospectively. The principles outlined in the Declaration of Helsinki were followed. Informed consent for surgery was obtained from the patients or their parents. The patients with minor ocular complications such as wound irregularities, conjunctivitis, subconjunctival hemorrhage and follow-up periods of less than six months were not included in the study.

All patients underwent full ophthalmic and orthoptic examination before and after the surgery. Ocular movements were assessed. Best corrected visual acuity was determined with Snellen letters, numbers, pictures, or was noted as central, steady and maintained fixation. Ocular deviation was examined with simultaneous prism cover test, Krimsky or Hirschberg corneal reflex tests depending on the age and level of cooperation. All measurements were made with and without refractive correction.

Surgical procedures were performed under topical, general or retrobulbar anesthesia. The patients were operated on using a conjunctival limbal approach, and the surgical techniques employed included recessions, resections, muscle advancements, inferior oblique myectomies, and muscle transpositions. Double-armed 6-0 polyglactin 910 (Vicryl, Ethicon, Somerville, NJ) sutures with spatula needle were used for sclera, while 8-0 polyglactin 910 (Vicryl, Ethicon, Somerville, NJ) for conjunctiva. Topical antibiotics and steroids were applied for 5 days after surgery. The patients were evaluated on postoperative days 1, 7, and every 3 months thereafter until the last follow-up.

\section{Results}

This case series is comprised of 1468 patients who underwent strabismus surgery. The ages of the patients ranged from 6 to 80 years. Recognized main ocular complications were noted in eight patients (0.5\%). Medial rectus rupture (Case 1), scleral perforation (Case 2), corneal dellen (Cases 3, 4, 5, 6, 7) and conjunctival cyst (Case 8) were the ocular complications. Clinical features of the patients are shown in the Table 1.

Case No. 1. An 80-year-old male patient presented with a history of 23-year-long chronic complete sixth nerve palsy secondary to trauma. Ocular versions demonstrated -4 limitation of the left eye in abduction. The ductions of the right eye were normal. Visual acuity was at 20/50 in the right eye, and 20/100 in the left eye. His

Table 1. Demographics and clinical findings of patients.

\begin{tabular}{|c|c|c|c|c|c|c|c|c|}
\hline $\begin{array}{l}\text { Case } \\
\text { no }\end{array}$ & $\begin{array}{l}\text { Age } \\
\text { (yrs) }\end{array}$ & Sex & Eye & Main disease & Surgery & $\begin{array}{l}\text { Preoperative } \\
\text { complication }\end{array}$ & $\begin{array}{l}\text { Postoperative } \\
\text { complication } \\
\text { (time) }\end{array}$ & $\begin{array}{c}\text { Follow } \\
\text { up (months) }\end{array}$ \\
\hline 1 & 80 & $\mathrm{M}$ & $\mathrm{L}$ & Sixth nerve palsy & - & Medial rectus rupture & - & 10 \\
\hline 2 & 61 & $\mathrm{~F}$ & $\mathrm{R}$ & $\begin{array}{c}\text { Sixth nerve palsy } \\
\text { Degenerative myopia }\end{array}$ & $\begin{array}{l}\text { Medial rectus } \\
\text { recession }\end{array}$ & $\begin{array}{l}\text { Scleral perforation } \\
\text { secondary to } \\
\text { retrobulber anesthesia }\end{array}$ & - & 12 \\
\hline 3 & 43 & $\mathrm{M}$ & $\mathrm{L}$ & Basic exotropia & $\begin{array}{l}\text { Lateral rectus recession } \\
\text { Medial rectus resection }\end{array}$ & - & $\begin{array}{l}\text { Corneal dellen } \\
\text { (first week) }\end{array}$ & 8 \\
\hline 4 & 22 & $\mathrm{M}$ & $\mathrm{L}$ & Basic exotropia & $\begin{array}{l}\text { Lateral rectus recession } \\
\text { Medial rectus resection }\end{array}$ & - & $\begin{array}{l}\text { Corneal dellen } \\
\text { (first week) }\end{array}$ & 65 \\
\hline 5 & 23 & M & $\mathrm{R}$ & Basic exotropia & $\begin{array}{l}\text { Lateral rectus recession } \\
\text { Medial rectus resection }\end{array}$ & - & $\begin{array}{l}\text { Corneal dellen } \\
\text { (first week) }\end{array}$ & 11 \\
\hline 6 & 26 & M & $\mathrm{L}$ & Basic exotropia & $\begin{array}{l}\text { Lateral rectus recession } \\
\text { Medial rectus resection }\end{array}$ & - & $\begin{array}{l}\text { Corneal dellen } \\
\text { (first week) }\end{array}$ & 32 \\
\hline 7 & 47 & $\mathrm{~F}$ & $\mathrm{~L}$ & $\begin{array}{c}\text { Consecutive } \\
\text { exotropia }\end{array}$ & $\begin{array}{c}\text { Lateral rectus recession } \\
\text { Medial rectus advancement }\end{array}$ & - & $\begin{array}{l}\text { Corneal dellen } \\
\text { (first week) }\end{array}$ & 6 \\
\hline 8 & 6 & $\mathrm{~F}$ & $\mathrm{~L}$ & $\begin{array}{c}\text { Partially refractive } \\
\text { esotropia }\end{array}$ & Medial rectus recession & - & $\begin{array}{c}\text { Conjunctival } \\
\text { cyst (4 months) }\end{array}$ & 142 \\
\hline
\end{tabular}

$\mathrm{M}=$ male; $\mathrm{F}$ = female; $\mathrm{R}$ = right; $\mathrm{L}$ = left. 
reduced vision was found secondary to bilateral nuclear sclerosis. Surgery was planned under general anesthesia for 85 prism diopters (PD) deviation. Forced duction test was positive for medial rectus muscle. Medial rectus rupture developed about $5 \mathrm{~mm}$ behind the insertion during medial rectus recession due to severe contracture of the muscle (Figure 1). Despite the rupture of the muscle, restriction continued in the forced duction test. We left the distal end of the ruptured muscle free in the subtenon space. However, no major change in the position of the globe was encountered on the postoperative examinations.

Case No. 2. This 61-year-old female has a 5-year history of chronic complete sixth nerve palsy secondary to diabetes mellitus and systemic hypertension. Ocular versions demonstrated -4 limitation of the left eye in abduction. The ductions of the right eye were normal. Corrected visual acuity was 20/640 with -20.00 diopter (D) refraction in both eyes. Her reduced vision was found secondary to bilateral degenerative changes of the fundus due to high myopia. Surgery was planned for 60 PD deviation under local anesthesia because the patient did not want general anesthesia. Following facial akinesia, retrobulbar anesthesia was applied. Force-duction test was positive for medial rectus muscle. We performed medial rectus recession of $6 \mathrm{~mm}$ and planned transposition of superior and inferior rectus muscles to the lateral rectus insertion after 6 months. On the first postoperative examination retinal break was observed suggesting a scleral perforation matching the lower temporal region of retrobulbar anesthesia. Laser therapy was applied immediately to the retinal break. Follow-up period was 16 months. No serious complications, such as vitreous hemorrhage, retinal detachment or endophthalmitis developed in this patient.

Cases No. 3, 4, 5, 6, 7. In these cases, corneal dellen developed postoperatively (first week); the ages of the patients were between 22 and 47 years. Their corrected visual acuities were 20/20 in both eyes, preoperative deviation angles ranged from 45 to 85 PD. Four of them (Cases 3, 4, 5, 6) had lateral rectus muscle recession combined with medial rectus muscle resection for basic exotropia. Other patient (Case 7) underwent $6 \mathrm{~mm}$ bimedial rectus recession 13 years ago for infantile esotropia. The ductions of the right eye were normal, while version demonstrated -2 limitation of the left eye in adduction. She had $7 \mathrm{~mm}$ lateral rectus muscle recession combined with medial rectus muscle advancement to the original insertion for consecutive exotropia in her left eye.

In all cases, corneal dellen disappeared in about 7 - 10 days, using topical lubricants and a firm bandage applied to the eye. There was no corneal pathology at the last follow-up examination.

Case No. 8. This 6-year-old girl had an uneventful $6 \mathrm{~mm}$ bimedial rectus muscle recession in both eyes for 55 PD of partially refractive accommodative esotropia. Corrected visual acuities with $+3.00 \mathrm{D}$ and $+1.50 \mathrm{D}$ were 20/20 in right and left eyes, respectively. Eye movements were normal. In primary position the patient had orthotropia at near and distance by cover test with her glasses and binocular single vision was present after strabismus surgery. Four months following the operation she presented a bluish-gray translucent mass occupying the nasal sector of her left eye (Figure 2(a)). Anterior segment, introcular pressure and fundus examinations were normal. There was no limitation of extraocular movements. Clinical appearance indicated a conjunctival cyst. The patient was asymptomatic and her parents preferred no intervention. We started prednisolone acetate $1 \%$ four times a day and the patient was observed intermittently. Conjunctival cyst improved with medical treatment, with no adverse side effects, and disappeared in about one month (Figure 2(b)).

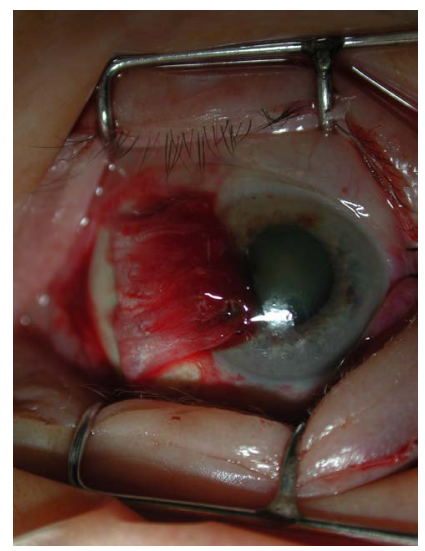

Figure 1. Medial rectus rupture during recession (Case 1). 


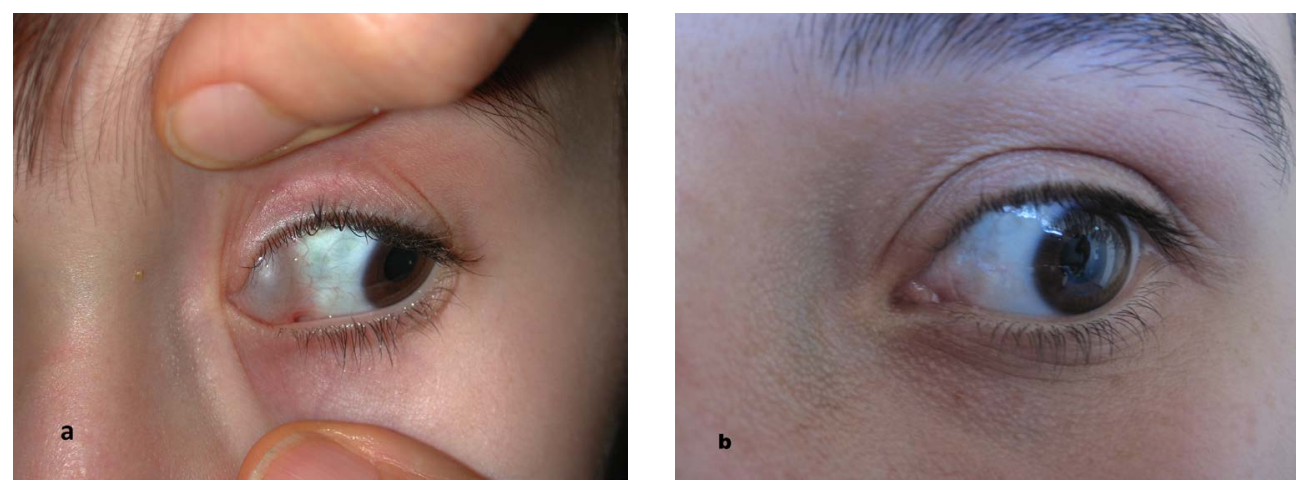

Figure 2. (a) Conjunctival cyst following medial rectus recession in the nasal sector of left eye (Case 8). (b) Appearance of the same patient (Case 8) after medical treatment with topical corticosteroid, with significant improvement noted.

\section{Discussion}

Vision-threatening complications are rare in strabismus surgery. The most serious complications are scleral perforation and penetration, and usually occur during muscle disinsertion or muscle reattachment [6]. The risk of perforation is increased in myopic eyes, and the risk is higher in recessions than in other strabismus procedures [6] [7]. Recent studies suggest that perforation has become less frequent up to $1 \%$, but probably occurs in many cases without the surgeon's awareness [4] [6] [7]. Compared to previous years lower incidence may be attributed to improved instruments and techniques used in strabismus surgery. The use of the spatulated needles and operating microscope or loopes has been advocated to control the depth of the needle pass in strabismus surgery [4] [5].

Other than muscle reattachment to the sclera with sutures, scleral perforation can also occur during peribulbar or retrobulbar injections [8]-[10]. Peribulbar anesthesia has been reported with fewer risks of ocular complications due to short needle presented, though presumed to be safer than retrobulbar injection, is not without risk of this complication. This is particularly important in myopic eyes due to thinned sclera and increased axial length [10]. Indirect ophthalmoscopy is necessary to identify any retinal changes indicative of a penetration or perforation. Timely detection and management of this complication is important, as the incidence of proliferative vitreoretinopathy is high. Therefore, a high index of suspicion is required in all cases of iatrogenic globe perforation as almost $48 \%-50 \%$ are not recognized at the time of occurrence [8]. In this study, we did not recognize any noticeable perforations or penetrations during strabismus surgery. However, scleral perforation with retinal break was developed in only one high myopic patient with chronic complete sixth nerve palsy during retrobulbar anesthesia. Globe perforation was not detected during anesthesia and strabismus surgery. It was observed on the first postoperative day. Laser therapy was immediately applied to the retinal break. No serious complications such as vitreous hemorrhage, retinal detachment or endophthalmitis developed in this patient. When choosing the method of anesthesia, it is very important to consider the effectiveness and safety of the methods. General or topical anesthesia is thought to be appropriate especially in patients with myopic cases.

Rupture or disintegration of an extraocular muscle is a very rare complication than the slipped or lost muscle during strabismus surgery. The medial rectus muscle is the most commonly injured muscle [11] [12]. Paysee and Coats [13] stated that the interstitial fibrosis of the muscle with secondary muscle fiber weakening and the restrictive nature of the strabismus surgery are probably the most important risk factors. One must be cautious when approaching these sorts of patients and ready to act if disintegration occurs. Muscle dehiscence is associated with various degrees of duction deficit. In our study, one patient experienced rupture of medial rectus that was tethered during medial rectus recession. However, no major change in the position of the globe was encountered. As the time from the onset of strabismus to surgical correction increases, the strength of fibrosis that fixates the globe medially seems to increase. It is perceivable that such patient may have less desirable outcome.

Corneal dellen is a shallow excavation at the margin of the cornea that occurs following localized interruption of the corneal tear film and local dehydration of the cornea. Fresina and Campos [14] reported the frequent occurrence of dellen formation after reoperations and transposition procedures. Tesler and Urist [15] stated that the incidence of dellen increased with the limbal approach. A limbal approach would seem to cause more desicca- 
tion than the more remote non-limbal approach. Furthermore, resections resulted in more dellen than recessions, as resections involved more tissue near the limbus than recessions do. Therefore, it has been recommended that the smooth closure of the limbal wound and resections (trimming) of excess limbal conjunctiva should prevent tissue elevation near the limbus [15]. In this study, corneal dellen was the most detected complications of strabismus surgery. Our patients were operated on using a limbal approach. Four patients had medial rectus muscle resection combined with lateral rectus muscle recession; one patient had lateral rectus muscle recession combined with medial rectus muscle advancement to the original insertion. Following this complication we suggest paying attention to excess of the conjunctiva near the limbus and postoperative examination of patients should not be delayed for more than one week to avoid possible corneal complications.

Another known rarely-recognized complication of strabismus surgery, conjunctival cysts, typically occur at the site of muscle reattachment months or years after surgery. Their size induced limitation in motility, strabismus, and problems related to chronic exposure. Tumor size, cystic nature, and involvement of underlying structures can be determined by ultrasonography and radiographic imaging. It has been suggested that careful retraction of tissues may prevent this complication. They may disappear spontaneously, but persistent cases often require surgical excision [16]-[18]. In our case, conjunctival cyst occurred in the nasal sector four months after medial rectus recession for partially refractive accommodative esotropia. Conjunctival cyst improved with topical corticosteroids and disappeared in about one month.

\section{Conclusion}

In conclusion, ocular complications of strabismus surgery are uncommon, and treatable. Damage to ocular structures can be prevented by using meticulous surgical techniques. Close follow-up is required in all cases postoperatively.

\section{References}

[1] Bradbury, J.A. and Taylor, R.H. (2013) Severe Complications of Strabismus Surgery. Journal of American Association for Pediatric Ophthalmology and Strabismus, 17, 59-63. http://dx.doi.org/10.1016/j.jaapos.2012.10.016

[2] Coats, D.K. (2010) Strabismus Surgery Complications. International Ophthalmology Clinics, 50, 125-135. http://dx.doi.org/10.1097/iio.0b013e3181f0fa21

[3] Simon, J.W. (2010) Complications of Strabismus Surgery. Current Opinion in Ophthalmology, 21, 361-366. http://dx.doi.org/10.1097/icu.0b013e32833b7a3f

[4] Surachatkumtonekul, T., Phamonvaechavan, P., Kumpanardsanyakorn, S., Wonqpitoonpiya, N. and Nimmannit A. (2009) Scleral Penetrations and Perforations in Strabismus Surgery: Incidence, Risk Factors and Sequelae. Journal of the Medical Association of Thailand, 92, 1463-1469.

[5] Morris, R.J., Rosen, P.H. and Fells, P. (1990) Incidence of Inadvertent Globe Perforation during Strabismus Surgery. British Journal of Ophthalmology, 74, 490-493. http://dx.doi.org/10.1136/bjo.74.8.490

[6] Haugen, O.H. and Kjeka, O. (2005) Localized, Extreme Scleral Thinning Causing Globe Rupture during Strabismus Surgery. Journal of American Association for Pediatric Ophthalmology and Strabismus, 9, 595-596. http://dx.doi.org/10.1016/j.jaapos.2005.07.003

[7] Dang, Y., Racu, C. and Isenberg, S.J. (2004) Scleral Penetrations and Perforations in Strabismus Surgery and Associated Risk Factors. Journal of American Association for Pediatric Ophthalmology and Strabismus, 8, 325-331. http://dx.doi.org/10.1016/j.jaapos.2004.03.003

[8] Gadkari, S.S. (2007) Evaluation of 19 Cases of Inadvertent Globe Perforation Due to Periocular Injections. Indian Journal of Ophthalmology, 55, 103-107. http://dx.doi.org/10.4103/0301-4738.30702

[9] Schrader, W.F., Schargus, M., Schneider, E. and Tatjana, J. (2010) Risks and Sequelae of Scleral Perforation during Peribulbar or Retrobulbar Anesthesia. Journal of Cataract \& Refractive Surgery, 36, 885-889. http://dx.doi.org/10.1016/j.jcrs.2009.12.029

[10] Carvalho, K.M., Millan, T., Minguini, N. and Wakamatsu, T.H. (2008) Peribulbar versus General Anesthesia for Horizontal Strabismus Surgery. Arquivos Brasileiros de Oftalmologia, 71, 352-356. http://dx.doi.org/10.1590/s0004-27492008000300009

[11] MacEwen, C.J., Lee, J.P. and Fells, P. (1992) Aetiology and Management of the "Detached” Rectus Muscle. British Journal of Ophthalmology, 76, 131-136. http://dx.doi.org/10.1136/bjo.76.3.131

[12] Lenart, T.D. and Lambert, S.R. (2001) Slipped and Lost Extraocular Muscles. Ophthalmology Clinics of North America, 14, 433-442. 
http://dx.doi.org/10.1016/s0896-1549(05)70241-8

[13] Paysse, E.A. and Coats, D.K. (2000) Disintegration of the Inferior Rectus Muscle during Strabismus Surgery for Restrictive Hypotropia. Ophthalmic Surgery and Lasers, 31, 328-330.

[14] Fresina, M. and Campos, E.C. (2009) Corneal “Dellen” as a Complication of Strabismus Surgery. Eye, 23, $161-163$. http://dx.doi.org/10.1038/sj.eye.6702944

[15] Tessler, H.H. and Urist, M.J. (1975) Corneal Dellen in the Limbal Approach to Rectus Muscle Surgery. British Journal of Ophthalmology, 59, 377-379. http://dx.doi.org/10.1136/bjo.59.7.377

[16] Kushner, B.J. (1992) Subconjunctival Cysts as a Complication of Strabismus Surgery. Archives of Ophthalmology, 110, 1243-1245. http://dx.doi.org/10.1001/archopht.1992.01080210061025

[17] Song, J.J., Finger, P.T., Kurli, M., Wisnicki, H.J. and Iacob, C.E. (2006) Giant Secondary Conjunctival Inclusion Cysts: A Late Complication of Strabismus Surgery. Ophthalmology, 113, 1045-1049. http://dx.doi.org/10.1016/j.ophtha.2006.02.031

[18] Guadilla, A.M., de Liano, P.G., Merino, P. and Franco, G. (2011) Conjunctival Cysts as a Complication after Strabismus Surgery. Journal of Pediatric Ophthalmology and Strabismus, 48, 298-300. http://dx.doi.org/10.3928/01913913-20100818-02 
Scientific Research Publishing (SCIRP) is one of the largest Open Access journal publishers. It is currently publishing more than 200 open access, online, peer-reviewed journals covering a wide range of academic disciplines. SCIRP serves the worldwide academic communities and contributes to the progress and application of science with its publication.

Other selected journals from SCIRP are listed as below. Submit your manuscript to us via either submit@scirp.org or Online Submission Portal.
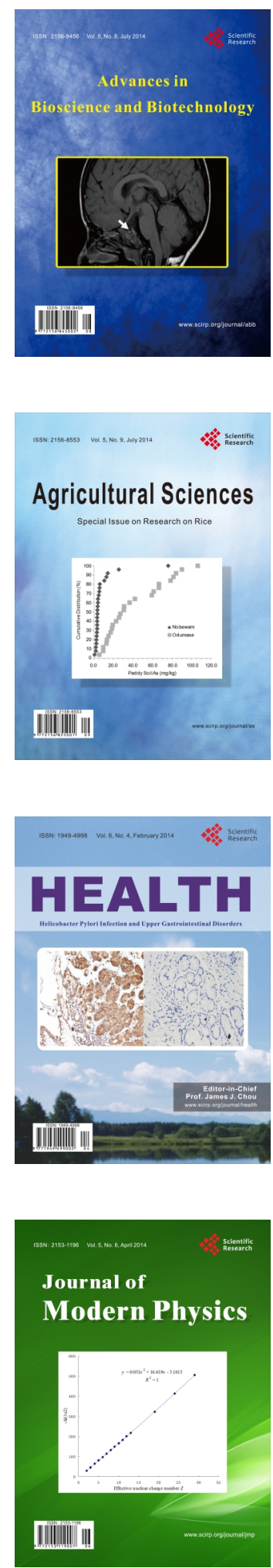
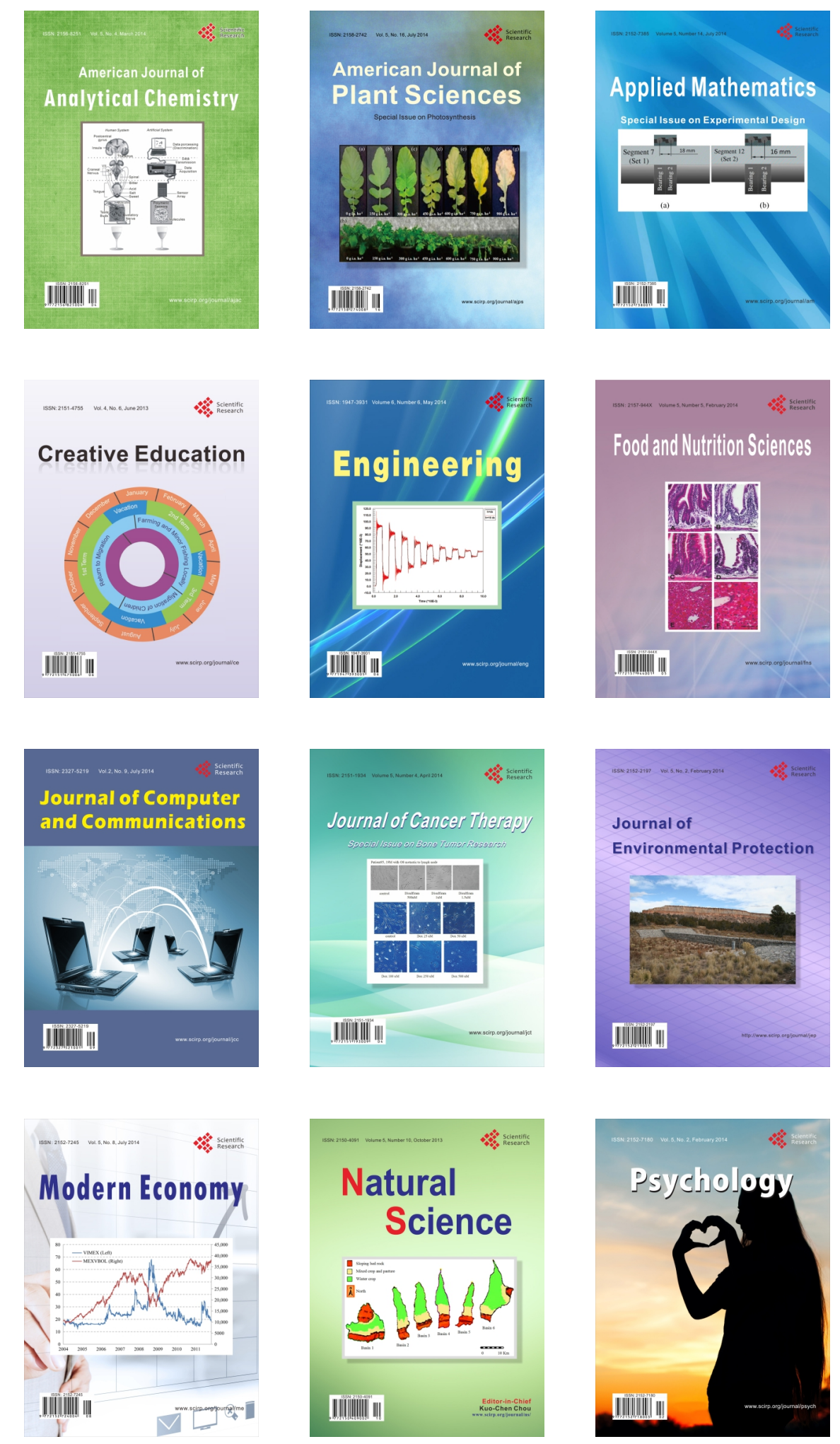